\title{
¿POLICIALIZAR O JUDICIALIZAR? REFLEXIONES SOBRE LA FASE DE INVESTIGACIÓN COMO PARTE DEL PROCESO PENAL EN VENEZUELA
}

Keymer Ávila*

Resumen: Ante la promulgación del Decreto con Rango, Valor y Fuerza de Ley Orgánica del Servicio de Policía de Investigación, el Cuerpo de Investigaciones Científicas, Penales y Criminalísticas y el Servicio Nacional de Medicina y Ciencias Forenses (LOSPI) y la última reforma del Código Orgánico Procesal Penal (COPP), ambos publicados en junio de 2012, surge la interrogante: ¿la investigación penal debe ser entendida como parte del servicio de policía o como una fase del proceso penal? En el presente trabajo se hace una reflexión crítica sobre la misma.

Palabras clave: investigación penal, proceso penal, policialización, administrativización.

* Abogado Magna cum Laude por la Universidad Central de Venezuela (UCV). Máster Oficial en Criminología y Sociología Jurídico Penal por la Universitat de Barcelona (UB). Estudios de posgrado en Ciencias Penales y Criminológicas y en Gobierno y Políticas Públicas en la Universidad Central de Venezuela. Investigador del Instituto de Ciencias Penales de la UCV y profesor de la Cátedra de Criminología de la UCV y de la Universidad Católica Andrés Bello (Caracas, Venezuela). Investigador acreditado del Programa de Estímulo a la Innovación e Investigación (PEII) del ONCTI. Colaborador del Observatorio del Sistema Penal y los Derechos Humanos de la UB. E-mail: keymerguaicaipuro@ gmail.com. Fecha de recepción: 2 de agosto de 2014. Fecha de modificación: 28 de noviembre de 2014. Fecha de aceptación: 16 de diciembre de 2014. Para citar el artículo: KeYMER ÁviLA. “Policializar o judicializar? Reflexiones sobre la fase de investigación como parte del proceso penal en Venezuela". Revista Derecho Penal y Criminología, vol. 35, n. ${ }^{\circ}$ 99, julio-diciembre de 2014, Bogotá, Universidad Externado de Colombia, 2014, pp. 157-185. DOI: http://dx.doi.org/10.18601/ 01210483.v35n99.07 


\title{
¿POLICIALIZE OR JUDICIALIZE? REFLECTIONS ON THE INVESTIGATION PHASE AS PART OF PENAL PROCESS IN VENEZUELA
}

\begin{abstract}
With the enactment of Decree with Rank, Value and Force of Law of the Police Service of Investigation, the Scientific and Criminal Investigations, and National Medicine Service and Forensic Science (LOSPI) and the latest reform of the Organic Code of Penal Procedure (COPP), both of them published in June 2012, this question arises: The penal investigation should be understood as part of the police service or as a phase of the penal process? This paper offers a critical approach of this matter.

Keywords: Penal investigation, penal process, police service, administrationalize.
\end{abstract}

\section{LA FASE DE INVESTIGACIÓN COMO PARTE DEL PROCESO PENAL}

El COPP en su primer artículo hace alusión al debido proceso y en los artículos siguientes desarrolla algunos de los derechos que este consagra, tal como la presunción de inocencia (art. 8), el derecho a la defensa (art. 12) o el principio non bis in idem (art. 20). Para el presente análisis es relevante destacar que entre estos principios y garantías procesales se encuentra la titularidad de la acción penal en cabeza del Ministerio Público (art. 11), aspecto que será desarrollado más adelante.

Este COPP estuvo inmerso en la ola de reformas que se dieron en Latinoamérica durante los últimos quince años, en la que se han venido dando procesos de transformación en el sistema de justicia penal, y en donde un aspecto en común ha sido el cambio del modelo procesal penal inquisitivo a otro de carácter acusatorio. Sobre las distinciones entre uno y otro modelo son abundantes las explicaciones; si bien en la realidad estos modelos nunca aparecen en estado puro, como tipos ideales (Weber, 1904), es importante distinguirlos, para así poder enmarcar a la fase de investigación como parte del proceso penal. Con estos fines se presenta el siguiente esquema general: 


\begin{tabular}{|c|c|c|}
\hline & Sistema inquisitivo & Sistema acusatorio \\
\hline 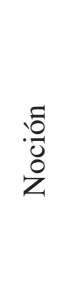 & $\begin{array}{l}\text { Es el sistema procesal en que el juez pro- } \\
\text { cede de oficio a la búsqueda, recolección } \\
\text { y valoración de las pruebas, llegándose al } \\
\text { juicio después de una instrucción escrita } \\
\text { y secreta de la que están excluidos o, en } \\
\text { cualquier caso, limitados la contradicción } \\
\text { y los derechos de la defensa. La prueba es } \\
\text { tarifada por ley. }\end{array}$ & $\begin{array}{l}\text { Es el sistema procesal que concibe al } \\
\text { juez como un sujeto pasivo rígidamente } \\
\text { separado de las partes y al juicio como } \\
\text { una contienda entre iguales iniciada por la } \\
\text { acusación, a la que compete la carga de la } \\
\text { prueba, enfrentada a la defensa en un juicio } \\
\text { contradictorio, oral y público, y resuelta } \\
\text { por el juez según su libre convicción. }\end{array}$ \\
\hline 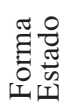 & $\begin{array}{l}\text { Expresión procesal del Estado de Policía: } \\
\text { derecho penal máximo. }\end{array}$ & $\begin{array}{l}\text { Expresión procesal del Estado social de } \\
\text { derecho: derecho penal mínimo. }\end{array}$ \\
\hline $\begin{array}{l}\stackrel{0}{\Xi} \\
\frac{0}{0} \\
\frac{0}{0} \\
\frac{0}{0} \\
\Sigma\end{array}$ & $\begin{array}{l}\text { Modelo autoritario heredero tanto de prác- } \\
\text { ticas como de doctrinas, patrones teóricos } \\
\text { y políticos premodernos antitéticos del } \\
\text { garantismo penal, inspirados desde la In- } \\
\text { quisición a las más modernas teorías de la } \\
\text { prevención especial o del tipo normativo } \\
\text { de autor, en sus múltiples variantes. }\end{array}$ & $\begin{array}{l}\text { Modelo garantista heredero de la Ilustra- } \\
\text { ción y el liberalismo político, que desde el } \\
\text { plano axiológico busca delimitar el poder } \\
\text { punitivo del Estado, identificándose con re- } \\
\text { gímenes democráticos y con las promesas } \\
\text { de la modernidad, al estar relacionado con } \\
\text { el principio de estricta legalidad penal y el } \\
\text { correspondiente proceso de formalización } \\
\text { y tipificación de los delitos y de las penas }\end{array}$ \\
\hline 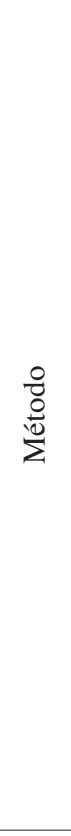 & $\begin{array}{l}\text { Esquema decisionista: el que juzga es un } \\
\text { órgano activo en la investigación de la } \\
\text { verdad sustancial, informada por criterios } \\
\text { esencialmente discrecionales; la actividad } \\
\text { instructora puede muy bien ser secreta, } \\
\text { interesando más la decisión justa que su } \\
\text { controlabilidad; el papel de la defensa } \\
\text { resulta irrelevante o, peor todavía, se con- } \\
\text { sidera un obstáculo para la buena marcha } \\
\text { del juicio; el objeto privilegiado del proceso } \\
\text { no es el hecho-delito sino la personalidad } \\
\text { del criminal reo. } \\
\text { El juicio se remite mucho más a la autori- } \\
\text { dad del juez y a sus juicios de valor que a } \\
\text { la verificación empírica de los supuestos } \\
\text { típicos acusatorios. } \\
\text { El método inquisitivo expresa una con- } \\
\text { fianza tendencialmente ilimitada del poder } \\
\text { como fuente autónoma de verdad. } \\
\text { Las pruebas se practican en secreto y por } \\
\text { escrito. }\end{array}$ & $\begin{array}{l}\text { Esquema cognoscitivo: la legitimidad del } \\
\text { poder judicial y de sus pronunciamientos } \\
\text { se fundamenta en la verdad, inevitable- } \\
\text { mente aproximativa o relativa. El contra- } \\
\text { dictorio entre las pruebas de las partes y } \\
\text { sus refutaciones es una condición nece- } \\
\text { saria. Los actos jurisdiccionales constan } \\
\text { de proposiciones asertivas, susceptibles } \\
\text { de verificación. Esto requiere de proce- } \\
\text { dimientos de control mediante prueba y } \\
\text { refutación, que solo un proceso de partes } \\
\text { fundado sobre el conflicto institucional } \\
\text { entre acusación y defensa puede garantizar } \\
\text { Se concentra más en la verificación empí- } \\
\text { rica de los supuestos acusatorios que en } \\
\text { la autoridad del juez. } \\
\text { El método acusatorio se caracteriza por } \\
\text { una desconfianza ilimitada del poder como } \\
\text { fuente autónoma de verdad. } \\
\text { Se caracteriza también por garantías como } \\
\text { la oralidad,la inmediación y la publicidad } \\
\text { de las pruebas. }\end{array}$ \\
\hline 苞 & $\begin{array}{l}\text { La verdad se confía a las virtudes del poder } \\
\text { que juzga. }\end{array}$ & $\begin{array}{l}\text { La verdad es el resultado de una contro- } \\
\text { versia entre partes contrapuestas. }\end{array}$ \\
\hline
\end{tabular}




\begin{tabular}{|c|c|c|}
\hline & Sistema inquisitivo & Sistema acusatorio \\
\hline 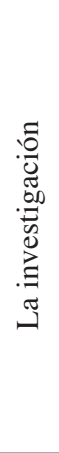 & $\begin{array}{l}\text { Se caracteriza por la centralidad de la } \\
\text { función del juez criminal, encargado de } \\
\text { indagar las denuncias, investigar, tomar } \\
\text { decisiones, autorizar allanamientos, reco- } \\
\text { pilar las pruebas y resolver el caso, a través } \\
\text { de un expediente escrito y en gran parte } \\
\text { secreto, donde se registran las actuaciones } \\
\text { que el mismo juez desarrolla (juez de ins- } \\
\text { trucción), concentrando de esta manera una } \\
\text { gran cuota de poder sobre el proceso penal, } \\
\text { porque el mismo es a la vez investigador y } \\
\text { custodio de sí mismo. }\end{array}$ & $\begin{array}{l}\text { Supone que una agencia especializada, el } \\
\text { Ministerio Público, recopila las pruebas y } \\
\text { plantea la acusación. Un órgano judicial } \\
\text { completamente diferente resuelve sobre } \\
\text { esta última, después de un juicio oral y } \\
\text { público donde el acusador y el acusado } \\
\text { pueden hacer valer sus planteamientos } \\
\text { y pruebas. En este modelo hay una dis- } \\
\text { tribución más equitativa de poder dentro } \\
\text { del proceso penal. }\end{array}$ \\
\hline 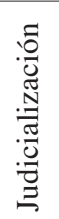 & $\begin{array}{l}\text { Tendencia a la administrativización del } \\
\text { derecho y del proceso penal. }\end{array}$ & $\begin{array}{l}\text { Tendencia a la judicialización }{ }^{+} \text {del derecho } \\
\text { y el proceso penal. }\end{array}$ \\
\hline
\end{tabular}

+ Muy en sintonía con el principio de jurisdiccionalidad en sentido estricto, que correspondería a un modelo procesal garantista, presente en la obra de Ferrajoli y que se explicará más adelante.

Fuente: elaboración propia, con contenidos de FERRAJOLI (2001), BINDER (1993) y Riego (1999).

Fue el modelo acusatorio el que se intentó implementar en el país desde 1998, y uno de los aspectos más importantes de este cambio fue la concepción de la fase preparatoria o de investigación, así como la de ejecución de la sentencia, como partes del proceso penal, judicializando y envistiendo de todas las garantías procesales a las mismas. Interesa concentrarse a efectos del presente análisis solo en la primera.

\subsection{La fase de investigación y su judicialización}

Antes de justificar la judicialización de la fase de investigación es necesario conocer qué debe entenderse por judicialización.

\subsubsection{La judicialización}

Por judicialización se quiere significar el proceso mediante el cual el juez penal conoce del caso, controlando la le galidad de cada una de las actuaciones de las partes, garantizando de esta manera los derechos de las mismas, velando especialmente por los derechos de los más vulnerables que se encuentren involucrados.

Es esta la idea de jurisdiccionalidad que explica FERRAJOLI en su clásica obra Derecho y Razón. Este autor señala que la primera enunciación legal de este principio se encuentra en el artículo 39 de la Magna Charta de 1215, la cual establecía: 
Ningún hombre libre será detenido ni preso, ni desposeído de sus derechos, ni posesiones, ni declarado fuera de la ley, ni exiliado, ni modificada su posición de cualquiera otra forma, ni Nos procederemos con fuerza contra él, ni mandaremos a otros a hacerlo, a no ser por un juicio legal de sus iguales o por la ley del país (2001, p. 539, resaltado propio).

Luego de esta cita, FERRAJOLI señala que el principio de jurisdiccionalidad contiene tres garantías fundamentales:

a) El habeas corpus, esto es, la inmunidad del ciudadano frente a restricciones arbitrarias de su libertad personal y, en general, frente a castigos o intervenciones de autoridades que lesionen sus derechos;

b) La reserva de jurisdicción en materia penal, es decir, la atribución de la averiguación y represión de los delitos únicamente al "juicio legal” de un sujeto imparcial e independiente, $\mathrm{y}$

c) La presunción de inocencia, en virtud de la cual nadie puede ser tratado o castigado como culpable, sin un "juicio legal” y antes de que este concluya.

Estas tres garantías: "no hay pena, no hay delito, no hay culpa sin juicio", expresan en su conjunto lo que FERRAJOLI denomina el "principio de jurisdiccionalidad en sentido lato". Que a su vez integra también "garantías orgánicas", las cuales son las relativas a la formación del juez, a su colocación institucional respecto a los demás poderes del Estado y a los otros sujetos del proceso: "independencia, imparcialidad, responsabilidad, separación entre juez y acusación, juez natural, obligatoriedad de la acción penal, etc.” (ibíd., pp. 539-540).

En contraste con la jurisdiccionalidad en sentido lato, FERRAJOLI concibe también el "principio de jurisdiccionalidad en sentido estricto", que tiene que ver con "los procedimientos y las garantías de los que depende el carácter cognoscitivo o declarativo del juicio", conformado a su vez por tres tesis: "no hay juicio sin acusación, sin pruebas y sin defensa"; agrupa también un conjunto de garantías que el maestro italiano denomina "procesales", que son las que tienen que ver con la formación del juicio, "es decir, a la recolección de pruebas, al desarrollo de la defensa y a la convicción del órgano judicial: como la formulación de una acusación exactamente determinada, la carga de la prueba, el principio de contradición, las formas de los interrogatorios y demás actos de instrucción, la publicidad, la oralidad, los derechos de la defensa, la motivación de los actos judiciales, etc." (ídem, resaltado propio).

Algunas de las mencionadas garantías procesales, tales como la orgánica separación entre juez y acusación y las procesales de publicidad, oralidad y contradicción en la formación de la prueba son propias del método acusatorio; de igual manera, algunas garantías orgánicas: independencia, imparcialidad, necesidad de la prueba y simila- 
res, si bien pueden ser comunes a todo tipo de proceso, son más plenas en el método acusatorio y disminuidas por el inquisitivo. Es por ello que FERRAJOLI identifica a la estricta jurisdiccionalidad con el modelo procesal garantista, que se expresa en el sistema acusatorio. Tanto es así que el maestro italiano concluye: "Mientras la jurisdiccionalidad en sentido lato es una exigencia de cualquier tipo de proceso, sea acusatorio o inquisitivo, la jurisdiccionalidad en sentido estricto supone la forma acusatoria del proceso" (ibíd., p. 539) ${ }^{1}$.

En la obra del referido autor también destaca el cognoscitivismo procesal como un elemento significativo dentro del principio de jurisdiccionalidad estricta. Este tiene que ver con las "motivaciones" de los pronunciamientos jurisdiccionales en materia penal, es decir, las razones de hecho y de derecho acogidas para su justificación. Para ello se exigen dos condiciones: la verificabilidad o refutabilidad de las hipótesis acusatorias en virtud de su carácter asertivo (como consecuencia del contradictorio) y su prueba empírica en virtud de procedimientos que permitan tanto la verificación como la refutación.

Explicada ya la idea de la judicialización, a continuación se expondrá la necesidad de judicializar a la fase de investigación penal.

\subsubsection{Necesidad de judicializar la fase preparatoria o de investigación}

El proceso penal integra un todo, cuya primera fase, preliminar o preparatoria, la constituye la instrucción (MARTín y MARTín, 2004, p. 57)². Roxin (2003) plantea esta misma idea de la siguiente forma:

1 Aunque más adelante aclara: "la dicotomía ‘jurisdiccionalidad estricta'/'jurisdiccionalidad lata' no coincide por tanto con la de 'acusatorio'/ inquisitivo' [...] sino que corresponde más bien a la que es, quizá, más importante de cognoscitivismo y decisionismo: 'jurisdiccionalidad estricta' tiene en efecto un significado más restringido que 'proceso acusatorio', mientras que 'jurisdiccionalidad lata' tiene un significado más amplio que "proceso inquisitivo"” (ibíd.).

2 MARTín y MARTín aborda la discusión doctrinal acerca de la naturaleza jurídica de la instrucción, distinguiendo entre las siguientes posturas: a) administrativa: al iniciarse de oficio está carente del ejercicio de la acción, lo que en ella se averigua no tiene valor probatorio y tampoco alcanza el efecto de cosa juzgada, lo que constituye un obstáculo para que sea concebida como proceso; b) preprocesal: se entiende que en la instrucción no existe aún una verdadera relación jurídica procesal, ya que las personas que en ella intervienen todavía no han de considerarse sujetos de tal relación; muchos autores consideran esta posición sin significado dogmático alguno; c) procesal: es la que tiene mayor predicamento, "precisamente al entender que el proceso se inicia desde el auto de incoación del sumario o del procedimiento, como resolución motivada y nunca de mero trámite, con diversas fases y períodos del procedimiento hasta llegar a la sentencia o en su caso al sobreseimiento, estando formado el proceso penal 'por dos partes bien definidas y delimitadas, una de investigación probatoria y otra de examen de esa prueba y de pronunciamiento de la resolución correspondiente, lo que no quiere decir que se trate de actividad de naturaleza jurisdiccional o funcional distinta [...] la instrucción por quedar enmarcada dentro del proceso, con finalidad propia pero no sólo al servicio de la fase plenaria, sino incrustada en la misma médula del procedimiento criminal [...] constituyendo a lo más la fusión de dos acciones, una acción introductiva al proceso penal propiamente dicho, mientras 
... la primera etapa de un procedimiento penal está constituida por el procedimiento preliminar [...] este procedimiento consiste, tan sólo, en el procedimiento de investigación a cargo de la fiscalía. [...] El procedimiento de investigación $[\ldots]$ se ha convertido [...] con frecuencia, en la parte esencial del proceso penal. [...] [E]n la mayoría de los casos, le da al fiscal el poder de decidir sobre el destino futuro del procedimiento. Además, a menudo, cuando se llega al juicio oral, su resultado está delineado ya por los resultados de la investigación del procedimiento preliminar. Por ello, es imperiosamente necesario darles al imputado y al defensor mayores posibilidades de influir sobre el procedimiento de investigación (pp. 325-326).

En este sentido, la jurisdiccionalidad estricta o judicialización del proceso penal, a la que ya se ha hecho referencia, debe abarcar todas las fases del mismo, para que este esté investido de todas las garantías durante su curso; de allí la importancia de judicializar la fase preparatoria o de investigación del proceso penal ${ }^{3}$, en especial si este es de tipo acusatorio. Dejar el contradictorio y la judicialización del proceso solo para la fase de juicio sería una reedición del sistema inquisitivo; en este sentido FERRAJOLi cita a:

Pertile, Storia della procedura [...] que recuerda la división del proceso inquisitivo: "en el procedimiento preliminar o informativo no se buscaban más que las pruebas del cargo, dejando para la segunda fase, a la que se llamaba defensiva, las favorables a la inocencia del indagado; cuando un testigo hubiera depuesto a favor del reo, no se registraba la deposición”. Y era una característica específica del método inquisitivo que sólo en la segunda fase se admitiera al defensor y se permitiera al reo el examen de las actas (2001, p. 685).

En la fase de investigación ingresa la primera información que da nacimiento al proceso penal, ya sea a través de la denuncia, querella o de oficio; luego de estos actos iniciales mediante los cuales ha ingresado formalmente una hipótesis delictiva al sistema judicial, comienza un período netamente preparatorio, que consiste en un conjunto de actos orientados a determinar si existen razones para someter a una persona a juicio. Ese conjunto de actividades procesales preparatorias son denominadas de distintas maneras: sumario, procedimiento preparatorio, instrucción o investigación preliminar o preparatoria. Estos actos iniciales del proceso son los que fundamentarán la acusación del fiscal del Ministerio Público (BINDER, 1993). En esta fase ya existe una potencial afectación a derechos fundamentales del investigado, y consecuencialmente debe cumplirse con el debido proceso, tal como

que en plenario lo que se ejercita es la acción puniendi, siendo las dos en perfecta ensambladura la formación y contextura del proceso penal"” (p. 72). El citado autor termina tomando posición por este último criterio, al cual se suscribe el presente análisis y que se desarrollará en esta sección.

3 En este sentido ver también a PÉreZ Martínez, 1998. 
se establece en los artículos 49.1 de la Constitución de la República Bolivariana de Venezuela (CRBV) ("en todo estado y grado de la investigación y del proceso") y 120 ("El Ministerio Público está obligado a velar por dichos intereses en todas las fases"), 127.3 (el imputado tiene derecho a ser asistido desde los actos iniciales de la investigación por un defensor) y 264 (control judicial de la fase preparatoria -su judicialización-) del copp. Esto se debe a que durante el período preparatorio pueden darse cuatro tipos de actividades:

1. Actividades puras de investigación (averiguación del hecho punible, reunión del material probatorio).

2. Decisiones que influyen sobre la marcha del procedimiento.

3. Anticipos de prueba, es decir, prueba que no puede esperar su producción en el debate (art. 289 COPP), lo que significa que de cierta forma se anticipen también las condiciones básicas del juicio.

4. Decisiones o autorizaciones, vinculadas a actos que pueden afectar garantías procesales o derechos constitucionales (medidas de aseguramiento personales, p. ej.) (Binder, 1993; Martín y Martín, 2004; VÁsqueZ, 2003).

Es importante destacar este último punto. BINDER explica que durante el desarrollo de la fase preparatoria deben tomarse decisiones, por ejemplo: cualquiera de los sujetos procesales puede plantear una excepción (de prescripción o de falta de acción) o cualquier otra clase de incidente. "Todos estos planteamientos obligan a tomar decisiones, que serán resoluciones a dictarse durante la instrucción. Una de ellas, quizás la más importante, es aquella resolución mediante la cual se decide que un imputado deberá permanecer en prisión o encarcelamiento preventivo" (1993, p. 215) 4

El procesalista argentino señala también la necesidad de tomar otro tipo de decisiones, esta vez no por causas incidentales, sino porque ciertos actos de investigación pueden afectar algunas garantías procesales, derechos o bienes protegidos por la Constitución. Por ejemplo: ingresar a un domicilio para localizar una prueba, tomar algún objeto o documento que pertenece a una tercera persona, o bien efectuar alguna investigación corporal o mental sobre el imputado o un testigo. Así entonces, en procura del respeto al debido proceso, y de la búsqueda de la afectación mínima posible de los derechos, se deben librar órdenes expresas y formales, por parte de la autoridad judicial, que permitan realizar estos actos de investigación. A estas decisiones BINDER las denomina autorizaciones jurisdiccionales (ibíd., p. 216), que no

4 Decisión sumamente importante si se consideran las altas tasas de presos sin condena y la delicada situación carcelaria de nuestros países, en particular la del sistema penitenciario venezolano. 
es más que una expresión de la judicialización de la fase de investigación a la que se está haciendo referencia y que es el argumento central de este trabajo.

Todo ello está íntimamente relacionado con la tutela judicial efectiva que debe existir en esta fase del proceso; en este sentido, MARTín y MARTín señala que la justificación de la instrucción es la "misma del proceso penal, y por tanto, como el único medio necesario para la realización de la Ley penal [...] de forma que el Tribunal Constitucional no ha dudado en afirmar que la instrucción forma parte de la tutela judicial efectiva" (2004, p. 61 $)^{5}$.

Por otra parte, es importante señalar que si bien la fase preparatoria no es una etapa eminentemente contradictoria como lo es el juicio, en esta deben existir igualmente amplias posibilidades de defensa: ello supone proponer diligencias, participar en los actos, plantear incidentes, etc. Igualmente, si bien esta etapa no es pública en el mismo sentido que lo es el juicio oral, tampoco se debe deducir que es secreta para los distintos sujetos procesales. Al contrario, el defensor, el querellante, las partes civiles, deben tener acceso al desarrollo de la investigación. Esto no obsta que esta posibilidad tenga mínimas y lógicas limitaciones, porque existen ocasiones en las que la eficacia de un acto o una investigación concreta depende del secreto, lo que debe estar regulado en la ley, por ejemplo, con el establecimiento por un tiempo determinado del secreto de ciertas actuaciones, aun para los intervinientes del proceso (BINDER, 1993, p. 219).

En este sentido, ZERPA, cuando analiza las distintas garantías que integran el debido proceso, resalta el derecho de ser notificado de los cargos de investigación (art. 49.1 CRBV), como parte del derecho a la defensa “aún en los 'grados' iniciales de investigación, ya que el carácter inviolable de la defensa frente a la imputación [...] alude a la perennización de este derecho 'en todo estado y grado de la investigación' [...] la necesidad de la notificación investigativa se asume como un componente prístino del derecho a la defensa, y por ende, reclamable a través de la garantía suprema al debido proceso" (2007, pp. 121-122).

Cuando BINDER da su explicación sobre esta primera fase del proceso penal que se está analizando, señala que es "preparatoria" porque los elementos de prueba que allí se reúnen no valen aún como prueba. Entonces, ¿sería preparatoria de qué? Para él es preparatoria de la acusación. El juicio es, pues, el momento de la prueba, en un sentido sustancial. Lo anterior "no es sino una recolección de los elementos que servirán para probar la imputación en el juicio; ése es, precisamente, el sentido de las palabras 'preparatorio de la acusación', con las que calificamos al procedimiento previo al juicio” (p. 216). Esto guarda mucha relación con la distinción entre actos de investigación y actos de prueba a la que se hará referencia más adelante.

5 En especial si se considera que "el real ejercicio de la jurisdicción es aquella que tutela una respuesta forense después de un trámite procesal [...], que debe ser equitativa, razonable, idónea, expedita, tal cual lo ordena el aparte del 26 Constitucional" (Zerpa, 2007, p. 119). 
Sobre el carácter preparatorio de esta fase, MARTín y MARTín va más allá, argumentando que en esta “"se prepara tanto el juicio como el no juicio', pues es sabido que de muchas instrucciones se sigue lo contrario, es decir el sobreseimiento" (2004, p. 61). Todo lo expuesto fortalece la tesis aquí sostenida sobre la necesidad de judicializar esta fase del proceso penal en procura de garantizar los derechos del investigado.

La fase preparatoria finaliza con el acto conclusivo del fiscal del Ministerio Público: acusación (acto mediante el cual se requiere la apertura del juicio), sobreseimiento (acto en el que el fiscal manifiesta que no hay elementos para acusar, constituyéndose en una absolución anticipada), archivo (la investigación no llega a ninguna de las dos situaciones anteriores, lo que implica una clausura provisoria de la investigación hasta que aparezcan nuevos elementos de prueba) (BINDER, 1993).

Finalmente, se debe tener en cuenta que en la realidad, la operatividad de nuestros sistemas procesales termina haciendo una conversión automática en "prueba" de los elementos reunidos en la investigación, sin que estos sean producidos directamente en juicio. De este modo, en la práctica, se dictan sentencias basadas casi con exclusividad en el "sumario". Lo que en palabras de BINDER serían sentencias inconstitucionales (ibíd., p. 217). Esta situación no solamente obliga a evitar que la fase de juicio consista solo en una legitimación automática de la fase preliminar, sino que además se debe prestar un especialísimo cuidado en esta primera fase que en mucho termina definiendo todo el proceso penal. No en vano Roxin señala que "cuando se llega a fallos erróneos, la mayoría de las veces ello se debe a que ya en el procedimiento de investigación se ha tomado un camino equivocado" (2003, p. 334).

El análisis de esta fase del proceso penal, que se inicia desde que se tiene noticia de la existencia de un delito y que se extiende hasta el momento en que se decide la presentación del acto conclusivo (PÉREZ SARMIENTO, 2007), no puede pasar por alto la interesante distinción entre actos de investigación y actos de prueba (VÁSQUEZ, 2003). A efectos del presente análisis interesa destacar respecto de los actos de investigación, que si bien no pueden considerarse pruebas por ser el juicio el momento de estas, es innegable su vocación probatoria, y de allí su relevancia jurídico-procesal. Estos constituyen la base de los actos conclusivos que determinarán o no la apertura de la fase de juicio, luego estos medios de prueba se transforman en los elementos probatorios que servirán para formar el convencimiento del juez sobre los hechos objeto del proceso, incidiendo entonces de manera esencial sobre el proceso penal, quedando sujetos al régimen jurídico de los actos procesales regulados por el COPP, lo que ratifica a su vez su necesaria judicialización.

Una vez concebida la investigación como una fase fundamental del proceso penal y justificada, por ende, su judicialización, se pasa en la próxima sección a analizar una noción de la misma en un plano más operativo-conceptual y organizacional. 


\subsection{La investigación penal y los actores que en ella se involucran}

En diversos eventos sobre esta materia, incluso académicos, en consultas a nivel nacional a funcionarios policiales y del Cuerpo de Investigaciones Científicas Penales y Criminalísticas (CICPC), así como en conversaciones informales con estos y con otros operadores del sistema, se evidencia el trato indiferenciado que se les da a los términos investigación penal, investigación criminal, criminalística e investigación técnico-científica. Esta ausencia de conceptos claros y compartidos respecto a la investigación penal, la distinción entre esta y las labores de apoyo a la misma, podría traer dificultades prácticas respecto al desempeño de estas labores y la adecuada distribución de competencias entre las distintas agencias intervinientes en esta fase del proceso penal. De allí la necesidad de definir conceptualmente lo que debe entenderse por cada una de estas labores y qué le correspondería hacer a cada quien. Lamentablemente los recientes cambios legislativos en esta materia agudizan más las confusiones.

La investigación penal es el conjunto de diligencias ordenadas y dirigidas por el Ministerio Público, orientadas a la constatación del hecho punible con todas sus circunstancias, que puedan influir en la calificación jurídica y responsabilidad penal de los autores y demás participantes. Es una labor auxiliar del derecho penal y del derecho procesal penal, que deben ser garantizados por el fiscal del Ministerio Público y aplicados por el Poder Judicial. Su fin es la aplicación o no del castigo formal, competencia exclusiva de la jurisdicción. Así entonces, el derecho (penal y procesal penal) sería el marco, y la investigación penal sería una labor subordinada, de auxilio al mismo; es por ello que la literatura básica en ciencias penales la cataloga como “disciplina auxiliar del derecho penal” (Ávila, 2013).

Dentro de la investigación penal, que está inmersa en lo jurídico y que trasciende lo meramente técnico, se encuentran la investigación criminal ${ }^{6}$ y la investigación técnico-científica ${ }^{7}$, que están concentradas en los hechos materiales más que en el derecho, pero no fuera de él, en lo fáctico-empírico, en la demostración del nexo causal; por ello algunos las clasifican como "disciplinas causal-explicativas" de las

6 La investigación criminal sería el conjunto de diligencias orientadas al descubrimiento del delito a través del establecimiento de hipótesis, búsqueda y concatenación de indicios, entrevistas, identificación y seguimiento de autores o partícipes, establecimiento de nexos entre estos y los hechos, sin que sea necesaria la utilización de laboratorios técnico-científicos. Para algunos estaría muy cercana a la "policiología” por su carácter predominantemente empírico, direccionada más a identificar, perseguir, localizar y detener al o a los presuntos responsables; su espacio está en el campo de los hechos (ibíd.).

7 La investigación técnico-científica, en cambio, es el conjunto de diligencias orientadas a la comprobación científica del delito, sus características, reconstrucción histórica, identificación de sus autores o partícipes, aseguramiento de los objetos activos o pasivos vinculados con el mismo, así como la preservación y análisis de evidencias. Esta sería la conocida criminalística (en su acepción restringida), la cual aglutina una amplia gama de disciplinas científicas (biología, medicina, química, física, ingeniería, planimetría, informática, etc.); su espacio principal es el laboratorio (ibíd.). 
ciencias penales. Ambas se refieren al "arte de la pesquisa", son auxiliares de la investigación penal, su relación es de subordinación, de auxilio respecto a esta, le aportan pruebas, la orientan técnicamente. De igual manera, también se puede afirmar que entre las categorías mencionadas existe una relación de género y especie, en la que la investigación penal sería el género y la investigación criminal y técnico-científica son las especies o subtipos.

Tanto la investigación criminal como la técnico científica deberán ser realizadas principalmente por el CICPC, así como por otros órganos que, previa formación especializada, tengan competencias en materia de investigación penal establecidas por ley. En este sentido, se tiene un concepto marco que es la investigación penal, que se encuentra más en el mundo del derecho y que apunta hacia la pena formal que impone el Estado, la cual debe ser dirigida y llevada a cabo por el Ministerio Público. Esta a su vez es auxiliada por dos subtipos de investigación de carácter más fácticoempírico, como son la investigación criminal y la técnico científica. Cada una de ellas amerita una formación especializada y diferenciada que dista en mucho de la diseñada para las policías uniformadas (de carácter preventivo); por ello el órgano principal para estas labores debe ser el CICPC. Esto debe ser así porque los investigadores actúan una vez sucedidos los hechos (post delito, indagan sobre lo sucedido), en cambio las policías uniformadas actúan ex ante (de allí su carácter preventivo). En este contexto las policías uniformadas solo deben prestar labores de apoyo a la investigación (ÁvILA, 2013). Esta clara separación entre las labores preventivas y las de investigación, y la evitación de la promiscuidad de aparatos y de funciones, es un reflejo del sistema político de un país y sirve de indicador para distinguir entre un gobierno despótico y un régimen de libertades (FERRAJOLI, 2001, pp. 768-769). La importancia de esta distinción será retomada en la sección 2.2.2.

\subsection{El Ministerio Público y su actividad fiscal: el director de la investigación}

El juez de instrucción del sistema inquisitivo, impuesto por el viejo Código de Instrucción Criminal francés de 1808, que inspiró a los sistemas procesales penales de tradición continental, concebía que el juez de instrucción debe ser investigador y, por otra parte, custodio de las garantías procesales y constitucionales. Es decir, debía ser guardián de sí mismo, y esto generaba, a juicio de BINDER, algún tipo de ineficiencia. Es por ello que las orientaciones más modernas tienden a acabar con la rémora del juez de instrucción. El autor argentino señala que en gran medida el fracaso de los sistemas de investigación de nuestros sistemas procesales proviene del empecinamiento en mantener el sistema inquisitivo en la instrucción, aunque luego se le adose un juicio oral, que a la postre resulta distorsionado.

En contraste, el sistema acusatorio organiza de forma distinta la investigación, dividiendo las dos funciones básicas, de modo que sea el Ministerio Público el encargado de investigar, quedando reservada para el juez la tarea de autorizar o tomar decisiones, pero nunca investigar. 
Según BINDER, este sistema que se ha ido imponiendo en la mayoría de los sistemas procesales, en la práctica ha demostrado ser mucho más eficaz, tanto para profundizar la investigación como para preservar las garantías procesales.

En este modelo, como ya se ha señalado, los fiscales tienen la responsabilidad de la investigación, y los jueces, solo la responsabilidad de vigilar y controlar esa investigación. En este punto es importante retomar la idea de la jurisdiccionalidad estricta de FERRAJOLI, que se encuentra expresada en el sistema acusatorio, en donde destaca entre sus múltiples garantías orgánicas la separación entre juez y acusación, mediante la eliminación de la vieja figura del juez instructor, quien es reemplazado por un juez para las investigaciones preliminares, ajeno a su desarrollo posterior (BINDER, 1993, pp. 217-218).

Así entonces, en el sistema acusatorio el Ministerio Público se constituye en la agencia especializada que dirige la investigación penal. Como ya se ha explicado, esta última, al afectar derechos fundamentales, debe estar controlada jurisdiccionalmente, lo que a su vez le da carácter procesal a esta fase. Es esta investigación la que nutre y sustancia a la acusación, lo que coloca la carga de la prueba sobre los hombros de esta agencia.

En este sentido, FERRAJOLI, una vez explicada la separación entre el juez y la acusación, señala que de esta surge un reparto de papeles entre los tres sujetos del proceso: las partes, la acusación y la defensa, a quienes competen respectivamente la prueba y la refutación, y el juez tercero, al que le corresponde la decisión. En consecuencia, tres garantías procesales se derivan también de esta división: la formulación de la imputación, con la que se formaliza la hipótesis acusatoria y se hace efectiva la contradicción; la carga de la prueba de tal hipótesis, que pesa sobre el acusador; y el derecho a la defensa, atribuido al imputado (2001, p. 606). Las dos primeras corresponden al Ministerio Público, quien tiene entonces la carga de la imputación y de la prueba, que pesan sobre la acusación; son estas las primeras garantías procesales del juicio. Es por ello que el Ministerio Público pone en marcha el ius puniendi del Estado, y no solamente a través de la dirección de la investigación y el monopolio de la acción penal pública, sino que además todo ello lleva también consigo el deber de probar: ¿de probar qué? Todas las circunstancias, tanto las que inculpen como las que exculpen al imputado (art. 263 COPP), de allí que sea un órgano que debe actuar de buena fe, en representación no solo del interés general y de los derechos de la presunta víctima, sino también en procura de la protección de los derechos del presunto infractor. Es errada la lectura según la cual el Ministerio Público solo investiga para ejercer la acción penal, pues también debe hacerlo para comprobar los hechos y circunstancias favorables a la persona investigada (FERRAJOLI, 2001, p. 736), lo que supone que la primera etapa del proceso puede concluir con la proposición de una acusación pero también con un pedido de sobreseimiento o un archivo fiscal; es decir, la actividad del fiscal debe estar en todo caso regida por la imparcialidad (VÁsQUEZ, 2003, p. 364). Tal atribución de funciones se justifica en el hecho de que el objeto de esta fase 
impide que la actividad investigativa sea dejada en manos de particulares, pues en la búsqueda de la verdad no pueden sacrificarse los derechos de aquel que es objeto de persecución penal.

Al hilo de lo expuesto, depende del Ministerio Público el desarrollo de la fase preparatoria del proceso penal, ya que precisamente tiene la llamada "carga de la prueba" dentro del proceso penal acusatorio, teniendo por tanto el deber de probar la existencia del delito y la participación del imputado; y toda inexactitud o insuficiencia en el cumplimiento de esa obligación debe determinar una sentencia favorable al imputado, en razón de ese irrenunciable principio que es el in dubio pro reo, base de la presunción de inocencia (PÉREZ SARMIENTO, 2007,p. 41), debiendo ser este último concebido más bien como un imperativo general, que obliga a los operadores de justicia a darle un trato de inocente al imputado, sin lo cual sería inconcebible el debido proceso. Es así como se concibe la existencia del in dubio pro reo, que garantiza que la parte acusadora tenga que probar sus imputaciones más allá de toda duda razonable (ibíd., p. 34). Todo esto está íntimamente relacionado con el carácter de garante del debido proceso que tiene el Ministerio Público venezolano.

\section{EL MINISTERIO PÚBLICO VENEZOLANO COMO GARANTE DEL DEBIDO PROCESO: LA REFUNDACIÓN DE LA REPÚBLICA Y EL NUEVO EQUILIBRIO DE PODER}

Ya desde la Declaración de Derechos del Buen Pueblo de Virginia del 12 de junio de 1776 se previene en su apartado $\mathrm{V}^{\mathrm{o}}$ la necesidad de que permanezcan separados los poderes legislativo, ejecutivo y judicial del Estado. Asimismo en la Declaración de los Derechos del Hombre y del Ciudadano, aprobada por la Asamblea Nacional francesa el 26 de agosto de 1789, se considera que una sociedad carece de Constitución si no están asegurados los derechos de la sociedad ni establecida la separación de poderes (PÉREZ MARTíneZ, 1998, p. 162).

Es punto en común -y en ello es uniforme la doctrina progresista- que la división de poderes es saludable para la consolidación del Estado de derecho y de la democracia. En este marco, en el preámbulo de la Constitución de 1999 se consagra la refundación de la República y de todas sus instituciones; se crean, además, dos nuevos poderes: el Ciudadano y el Electoral, superando de esta manera la clásica división tripartita, aumentando formalmente el sistema de controles y contrapesos entre los poderes públicos.

El Poder Ciudadano tiene entre sus funciones la prevención, investigación y sanción de los hechos que atenten contra la ética pública y la moral administrativa. Se encarga básicamente de ejercer el control de la actividad administrativa del Estado y de promover la formación ciudadana. 
El Ministerio Público, junto con la Defensoría del Pueblo y la Contraloría General de la República, integra el Consejo Moral Republicano, institución a través de la cual se ejerce el Poder Ciudadano (arts. 273 CRBV y 1 y 2 Ley Orgánica del Poder Ciudadano).

La Defensoría del Pueblo se encarga, fundamentalmente, de demandar ante las instituciones del Estado el debido cumplimiento de sus funciones, en resguardo de los derechos colectivos y difusos de los ciudadanos. Por su parte, la Contraloría General de la República se ocupa de controlar y vigilar que los ingresos, gastos y la adquisición de bienes públicos se hagan bajo el estricto cumplimiento de los procedimientos legales en todos los órganos de la administración pública. Ambas instituciones, de acuerdo a la CRBV (arts. 281.4 y 289.4), le solicitan al Ministerio Público ejercer las acciones judiciales que tuvieran lugar en los casos conocidos en cada una de ellas (derechos humanos y delitos contra el patrimonio público).

Por otra parte, el Ministerio Público no solamente se encarga de hacer efectiva la responsabilidad del funcionario infractor, también se encarga de hacer efectiva la responsabilidad de cualquier ciudadano que cometa algún hecho punible.

De esta manera, la CRBV modela a un Ministerio Público formalmente autónomo e independiente, que contribuye al ejercicio de los pesos y contrapesos necesarios en un sistema democrático.

Así, la creación institucional de órganos que tienen como funciones el control administrativo del Estado (Consejo Moral Republicano), la investigación y la acción penal (Ministerio Público) o jurisdiccionales (Tribunal Supremo de Justicia), tiene una dimensión de contra-poder al servicio de la legalidad y de la protección de las personas. Esto es muy significativo desde una perspectiva de garantía de los derechos fundamentales, y a su vez está también íntimamente relacionado con la fortaleza democrática del sistema político.

En el tema que nos concierne, es fundamental destacar que en nuestro modelo de Estado, así como la función jurisdiccional es atribuida al Estado con carácter de exclusividad, correspondiendo al Poder Judicial su ejercicio con independencia del resto, con sujeción a determinados límites, controles y garantías, la función de investigar (dirección, supervisión y práctica), y consecuencialmente de accionar penalmente, corresponde al Ministerio Público ${ }^{8}$. Con semejante diseño político e institucional pudiera afirmarse que la CRBV prevé un sistema acusatorio para el país, que se aprecia en especial por la concepción que la misma establece sobre el Ministerio Público, y de las atribuciones que le confiere en el artículo 285: ordenar y dirigir la investigación

8 CRBV, artículo 285, numerales 3 y 4; COPP, artículos: 111, numerales 1, 2 y 3; 114, 116, 265, 266, 291 y 514, numerales 7 al 9; Ley Orgánica del Ministerio Público (LOMP), artículos: 16, numerales 3, 4, 5 y $6 ; 25$, numerales $10,13,14$ y $24,31.11,37$, numerales $6,9,10,11$ y 14 ; y el 53.1; LosPi, artículos: 40, 34, 35, numerales 2 y 3; Ley Orgánica del Servicio de Policía y Cuerpo de Policía Nacional Bolivariana (LOSPCPNB): artículo 33. 
penal (num. 3), la titularidad y ejercicio la acción penal (num. 4, en concordancia con el art. 11 COPP), garantizar en los procesos judiciales el respeto a los derechos y garantías constitucionales (num. 1) y garantizar la buena marcha de la administración de justicia, el juicio previo y el debido proceso (num. 2), competencias todas que coinciden plenamente con la jurisdiccionalidad estricta que FERRAJOLI establece como característica del sistema acusatorio, en el que el Ministerio Público es una pieza protagónica y fundamental.

Por otra parte, el Ministerio Público como garante del debido proceso (art. 285.2 CRBV) debe velar por todas las garantías constitucionales y procesales que forman parte del sistema acusatorio y de los límites del ius puniendi, tales como presunción de inocencia, derecho a la defensa, in dubio pro reo, principio de legalidad, non bis in idem, igualdad entre las partes, juicio previo (art. $49 \mathrm{CRBV}$ ), así como la tutela judicial efectiva (art. $26 \mathrm{CRBV}$ ), entre otras, en todo grado y fase del proceso, lo que abarca a la fase de investigación de la cual es el director.

En esta línea, FERRAJOLi dice que es necesario romper con un lugar común, a saber:

... la idea de que los órganos de la acusación deban ser estructurados jerárquicamente, e incluso depender de alguna articulación del poder ejecutivo o legislativo, sólo por el hecho de que se encuentran situados fuera del orden judicial. Al contrario, lo que se precisa, en garantía de la obligatoriedad de la acción penal y por tanto de su sujeción sólo a la ley, es también la total autonomía del órgano encargado de su ejercicio, frente a cualquier poder o condicionamiento, y, además, la existencia de una policía eficiente, profesionalizada, a su vez libre de las injerencias del ejecutivo o de otros poderes, situada bajo su control $\left(2001\right.$, p. 570) ${ }^{9}$.

Sobre esta independencia PÉREZ MARTínez afirma que la misma suele encontrar dificultades, tanto en la dimensión interna de cada estructura como en el orden externo, en la relación de control administrativo o judicial con los otros poderes del Estado. En efecto, es el ejecutivo quien dispone de la policía para gestionar la seguridad pública y, con ella, incide en el libre desarrollo de los derechos ciudadanos, pudiendo de hecho limitar, controlar o interferir en el proceso penal (a través de las actividades de investigación) que le resulte incómodo. De allí la necesaria separación entre las actividades policiales de carácter eminentemente preventivo y las de investigación que deben ser dirigidas por el Ministerio Público, quien entra en acción una vez. ocurrido el delito. En consecuencia, sus labores son de carácter procesal y por ende deben ser judicializadas para garantizar los derechos de los ciudadanos.

9 Sobre las relaciones entre el Ministerio Público y el órgano de investigaciones en Venezuela ver ÁvILA, 2012. 
En cuanto a la naturaleza de sus actuaciones, hay que tener en cuenta que el Ministerio Público es una institución "bisagra” entre el Poder Ciudadano (art. 273 CRBV) y el Sistema de Justicia (art. 253 CRBV) ${ }^{10}$; es la única institución del Poder Público Nacional con estas características, cuyos actos realizados desde el inicio de la investigación, es decir, en el curso del proceso penal, implican que los mismos "tienen naturaleza procesal" (VÁsQUEZ, 2003, p. 362) ${ }^{11}$. Se fortalece de esta manera el argumento principal del presente trabajo: la fase de investigación es parte del proceso penal y por lo tanto debe ser judicializada; la misma debe ser dirigida por el Ministerio Público, como garante de esta judicialización, y con ello se garantiza el debido proceso, en el marco de un sistema acusatorio como expresión procesal de un Estado Social de Derecho y de Justicia.

\section{TENDENCIAS HACIA LA "ADMINISTRATIVIZACIÓN" DEL PROCESO PENAL: LA "POLICIALIZACIÓN" DE LA INVESTIGACIÓN PENAL}

Wilson y Kelling, en su famoso artículo "Broken Windows", que se ha convertido en un referente del pensamiento criminológico más conservador y antigarantista, no solo subordinan a la comunidad bajo la lógica policial, sino que además también minimizan a la autoridad judicial ante la misma:

Normalmente, ningún juez ni jurado se topa con las personas involucradas en un conflicto acerca del nivel apropiado de orden en un barrio. Esto es cierto no sólo porque la mayoría de los casos se resuelven informalmente en las calles, sino también porque no existen criterios universales para guiar las disputas acerca del desorden, y un juez no sería entonces más idóneo o más eficiente que un policía (KeLLING/WiLson, 1982).

La anterior cita expresa claramente la idea de la administrativización de procesos que deben estar investidos de mínimas garantías judiciales, garantías que son vistas como obstáculos para un manejo eficiente de la conflictividad social. De allí que

10 Para Roxin la fiscalía es una autoridad de la justicia estructurada jerárquicamente (2003, p. 50). Más adelante afirma "La fiscalía es una autoridad de la justicia que no puede ser atribuida ni al ejecutivo ni al tercer poder, sino que se trata de un órgano independiente de la administración de justicia que está entre ambos [...] Pero la fiscalía tampoco es, en modo alguno, una mera autoridad administrativa. Dado que a ella le está confiada la administración de justicia penal, en división funcional con los tribunales, su actividad, como la del juez, no puede estar orientada a las exigencias de la administración, sino sólo a valores jurídicos, esto es, a criterios de verdad y justicia” (p. 53).

11 En el mismo sentido RIVERA señala: "conforme a las normas constitucionales citadas, la configuración del Ministerio Público no se relaciona con el ejercicio de potestades administrativas sino que marca su campo de actuación en el ámbito del proceso. Dice GIMENO SENDRA que la actuación del Ministerio Fiscal difiere de la de un órgano meramente administrativo, porque 'aun cuando no aplique la Ley tribunales-, le corresponde la función de provocar la actividad jurisdiccional y de que ésta se desarrolle a través del juez legal y procedimiento preestablecido"” (2008, p. 224). 
estos autores prioricen en otorgar más poderes a las policías, a la vez que se les resta autoridad a fiscales y jueces. Entre los procesos que se ven afectados por esta racionalidad se encuentra la fase de investigación penal.

Para desarrollar la idea de la administrativización del proceso penal, así como la policialización de su fase inicial, es necesario explicar primero cada uno de estos términos.

\subsection{La administrativización del derecho penal y del derecho procesal penal}

SILVA SÁnchez, en su obra La expansión del derecho penal (2006), y antes MIR PuIG, en El Derecho Penal en el Estado Social y Democrático de Derecho (1994), conciben a la administrativización del derecho penal como una flexibilización de los principios garantistas, que constituyen una conquista de la modernidad penal, en procura de una expansión punitiva de corte autoritario y represivo, que se expresa a través del incremento y ampliación de sanciones, delitos de peligro presunto para bienes supra individuales, entre otros.

Ambos autores, para explicar este fenómeno, contrastan las diferencias entre lo administrativo y lo penal, que se presentan panorámicamente en el siguiente esquema.

\begin{tabular}{|c|c|c|}
\hline & Lo administrativo & Lo penal \\
\hline $\begin{array}{l}\text { Modelo de } \\
\text { Estado }\end{array}$ & $\begin{array}{l}\text { Estado social autoritario: caracte- } \\
\text { rizado por subordinar al individuo } \\
\text { al todo social. }\end{array}$ & $\begin{array}{l}\text { Estado social democrático: le importan } \\
\text { los intereses colectivos en la medida } \\
\text { que los mismos estén al servicio del } \\
\text { individuo. }\end{array}$ \\
\hline $\begin{array}{l}\text { Derechos y } \\
\text { garantías. } \\
\text { Vulneración de } \\
\text { derechos funda- } \\
\text { mentales }\end{array}$ & $\begin{array}{l}\text { No hay mayores riesgos de vulne- } \\
\text { ración de derechos fundamentales. }\end{array}$ & $\begin{array}{l}\text { Debido a la posibilidad de afectación } \\
\text { de derechos fundamentales (como por } \\
\text { ejemplo, las sanciones privativas de } \\
\text { libertad) debe brindar mayores garan- } \\
\text { tías, tanto formales como materiales. }\end{array}$ \\
\hline $\begin{array}{l}\text { Autoridad que } \\
\text { decide }\end{array}$ & Administrativa & Judicial \\
\hline Lo teleológico & $\begin{array}{l}\text { La finalidad que persigue es la } \\
\text { ordenación, de modo general, de } \\
\text { sectores de actividad. }\end{array}$ & $\begin{array}{l}\text { La finalidad que persigue es la protec- } \\
\text { ción de bienes jurídicos concretos, en } \\
\text { casos concretos. }\end{array}$ \\
\hline $\begin{array}{l}\text { Bien jurídico } \\
\text { protegido }\end{array}$ & Colectivos, difusos & Individuales, concretos \\
\hline Lesividad & $\begin{array}{l}\text { Abstracta: atiende a consideracio- } \\
\text { nes de afectación general (peligro } \\
\text { presunto, estadístico, global); no } \\
\text { tiene por qué ser tan estricta en la } \\
\text { imputación (visión "macroeconó- } \\
\text { mica", "macrosocial", "grandes } \\
\text { cifras", "problemas estructurales" } \\
\text { o "sistémicos", etc.) Juicio ex ante. }\end{array}$ & $\begin{array}{l}\text { Concreta: criterio de lesividad o peli- } \\
\text { grosidad concreta y de imputación indi- } \\
\text { vidual de un injusto propio (imputación } \\
\text { personal de un sujeto determinado). No } \\
\text { interesa el aspecto estadístico, sino si } \\
\text { la persona cuya conducta se está enjui- } \\
\text { ciando puso realmente en peligro bienes } \\
\text { jurídicos concretos o no. Juicio ex post. }\end{array}$ \\
\hline
\end{tabular}




\begin{tabular}{|c|l|l|}
\hline & \multicolumn{1}{|c|}{ Lo administrativo } & \multicolumn{1}{c|}{ Lo penal } \\
\hline \multirow{2}{*}{$\begin{array}{c}\text { Criterio para la } \\
\text { persecución }\end{array}$} & $\begin{array}{l}\text { Criterios de oportunidad: lo que } \\
\text { se busca es que el género de con- } \\
\text { ductas represente, en términos es- } \\
\text { tadísticos, un peligro para el buen } \\
\text { orden del sector de actividad de- } \\
\text { terminado. }\end{array}$ & \\
\hline
\end{tabular}

Fuente: elaboración propia, con contenidos de SiLVA SÁnchez (2006) y MIR PUIG (1994, p. 157).

Mir PUIG explica cómo el principio de intervención mínima del derecho penal choca con la tendencia actual de utilizar al derecho penal como instrumento meramente sancionador de normas no penales (civiles, mercantiles, administrativas). Esto tiene que ver, por una parte, con la errada, torpe y nefasta interpretación que se hace sobre el Estado social o intervencionista ${ }^{12}$, que se traduce en lo concreto en un incremento de su actividad legislativa (como si los cambios sociales se hicieran solo por decreto y se materializaran a través del papel), la cual trata de ser asegurada con la implementación de sanciones penales a cualquier infracción de las nuevas normativas. Identificando de esta manera la hipertrofia legislativa con el grado de eficacia política de la gestión gubernamental, que en la realidad resulta todo lo contrario, porque termina colapsando al sistema penal e incrementa los costos sociales que produce toda criminalización (este fenómeno pudiera ser catalogado como una desviación autoritaria desde la izquierda). Por otro lado, paradójicamente esta racionalidad autoritaria también coincide con el neoliberalismo (derecha política), y desde esta perspectiva SILVA explica que actualmente estamos inmersos en la "sociedad del riesgo", "de la inseguridad", que conduce al "Estado vigilante" o "Estado de la prevención", cuyos procesos de privatización y de liberalización de la economía sirven de caldo de cultivo y acentúan estas tendencias. En este marco el derecho penal asume la lesividad global derivada de acumulaciones o repeticiones, tradicionalmente propia de lo administrativo (de allí el proceso de administrativización del derecho penal), a través del cual se busca gestionar los grandes problemas sociales, traducidos en cifras, no importando la lesividad del comportamiento individual. Esta "modernización” del derecho penal se caracteriza por la expansión y por la flexibilización de los principios políticos criminales y reglas de imputación, desnaturalizando el sistema de garantías del mismo. Así se visualiza que en la realidad las razones de izquierdas o de derechas se diluyen y entremezclan para coincidir ambas en la misma praxis autoritaria. En el texto de SILVA se pueden distinguir cuatro dimensiones de la administrativización del derecho penal: 1) El problema no es la lesividad del comportamiento individual sino las grandes cifras: delitos de peligro abstracto, y delitos de acumulación que

12 "Creo que ésta es una vía de razonamiento que debe atenderse si se quiere evitar la peligrosa tendencia que posee todo Estado social a hipertrofiar el Derecho penal a través de una administrativización de su contenido de tutela, que se produce cuando se prima en exceso el punto de vista del orden colectivo" (Mir Puig, 1994, p. 165). 
vulneran principios penales como la culpabilidad y la proporcionalidad; 2) Gestión de los grandes problemas sociales a través del derecho penal: la protección penal del "Estado de la prevención"; 3) El redescubrimiento de la inocuización; 4) Las soluciones de autorregulación que se presentan como alternativa eficiente a la estricta legalidad y a la jurisdiccionalidad. Los mencionados análisis se han concentrado solo en el derecho penal de carácter sustantivo, es por ello que en el presente ensayo se incluye una quinta dimensión de la administrativización del derecho penal: la administrativización del derecho penal adjetivo, consistente en mermar cada vez más las garantías propias del proceso penal, asemejándolo a un mero procedimiento administrativo controlado por el ejecutivo y sus órganos policiales.

De la administrativización del derecho penal, que sería una "segunda velocidad" para SILVA, puede pasarse fácilmente a una "tercera velocidad" que se expresa en el Derecho Penal del Enemigo ${ }^{13}$. Entre las principales características de este "Derecho" Penal del Enemigo se encuentra la flexibilización, relativización e incluso supresión de las garantías procesales (JAKOBS, 2004; GARCíA A., 2006; CANCIO, 2006).

Enmarcada en estas lógicas autoritarias de desmontaje de las garantías procesales en materia penal se manifestaría la policialización de determinadas fases del proceso penal, tal como ha sucedido con los recientes cambios legislativos en materia de investigación penal en Venezuela y que a continuación se describen.

\subsection{La policialización de la fase de investigación en Venezuela ${ }^{14}$}

Antes de hablar de la policialización (SAIN, 2008) se considera necesario distinguir esta idea del término policización (ZAFFARONI, 1998), ambos utilizados en nuestra región y que pueden ser fácilmente confundidos ${ }^{15}$.

13 “De acuerdo con su posición, en el momento actual se están diferenciando dos 'velocidades', en el marco del ordenamiento jurídico-penal: la primera velocidad sería aquel sector del ordenamiento en el que se imponen penas privativas de libertad, y en el que, según SiLVA Sánchez, deben mantenerse de modo estricto los principios político-criminales, las reglas de imputación y los principios procesales clásicos. La segunda velocidad vendría constituida por aquellas infracciones en las que, al imponerse sólo penas pecuniarias o privativas de derechos -tratándose de figuras delictivas de nuevo cuño-, cabría flexibilizar de modo proporcionado a la menor gravedad de las sanciones esos principios y reglas 'clásicos'. Con independencia de que tal propuesta pueda parecer acertada o no -una cuestión que excede de estas breves consideraciones-, la imagen de las 'dos velocidades' induce inmediatamente a pensar-como ya ha hecho el propio SiLva Sánchez- en el Derecho penal del enemigo como 'tercera velocidad', en el que coexistirían la imposición de penas privativas de libertad y, a pesar de su presencia, la 'flexibilización' de los principios político-criminales y las reglas de imputación” (CANCIO, 2006, pp. 114-115).

14 El análisis presente en esta sección forma parte de un proyecto de investigación más amplio. Para ver el impacto de la legislación objeto de estudio sobre el órgano de investigaciones respecto a sus relaciones de necesaria subordinación funcional al Ministerio Público, así como la policialización del mencionado órgano, ver ÁviLA, 2013.

15 Se agradece la esclarecedora y grata conversación con Roberto Manuel Carlés sobre la distinción entre ambos términos, así como la facilitación de su trabajo: "El gobierno local del delito en la Ciudad 
A través del término policización ZAFFARONI explica el proceso a través del cual la institución policial crea a sus policías, haciendo un paralelismo con los procesos de criminalización que crean delincuentes, desde una perspectiva claramente interaccionista. En el plano "formal" las instituciones policiales manejan un discurso moralizante; pero en la realidad, como consecuencia del rol que le asigna la "propaganda masiva trasnacionalizada" (violencia, no intervención judicial, solución ejecutiva de los conflictos, machismo, insensibilidad, etc.), se le exige al policía que su conducta sea la misma que la de un psicópata. Es así como se da un "proceso de deterioro al que se somete a las personas de los sectores carenciados de la población que se incorporan a las agencias militarizadas del sistema penal, consistente en deteriorarles su identidad originaria y reemplazarla por una identidad artificial, funcional al ejercicio de poder de la agencia" (1998, p. 145).

En contraste con este proceso subjetivo que forja al funcionario policial, Sain utiliza el término policialización para explicar el proceso a través del cual los gobiernos entregan a "la institución policial tareas básicas de dicho gobierno" en materia de seguridad ciudadana. Es el empoderamiento de la policía (mayor discrecionalidad, operatividad, recursos, incidencia en su diseño y desarrollo institucional, así como en las estrategias de control del delito, etc.) ante problemas sociopolíticos, los cuales son gestionados bajo una perspectiva predominantemente bélica y centralizada, orientada por los intereses de esta institución. Trayendo como consecuencia lógica un desgobierno político en procura de un autogobierno policial. En el presente análisis se adopta el término policialización desde la perspectiva del politólogo argentino, que apunta más a procesos institucionales y a lógicas de gestión.

Por policialización de la fase de investigación se entiende el proceso a través del cual esta fase del proceso penal trata de ser despojada de su carácter procesal y, consecuencialmente, de su necesaria judicialización, garantizada por la dirección del Ministerio Público en el marco del sistema acusatorio, para ser forjada como un procedimiento administrativo, tecnocrático, alejado del derecho y de instituciones jurídicas, desprendido de todas las garantías procesales y penales, para convertirse en una función meramente policial, ejercida autónoma y discrecionalmente por las agencias policiales, sin control externo ni jurisdiccional alguno.

En este proceso se pueden distinguir claramente dos dimensiones del fenómeno que operan de forma paralela y se retroalimentan entre sí: 1) Merma de la dirección del Ministerio Público sobre la investigación penal y del control de esta institución sobre el órgano de investigaciones; 2) Desjudicialización de la fase de investigación para concebirla como una mera función policial de carácter eminentemente tecnocrático.

Autónoma de Buenos Aires: retóricas participativas y policialización de la cuestión securitaria” (2013). 


\subsubsection{La merma de la dirección del Ministerio Público sobre la investigación penal y de su control funcional sobre el órgano de investigaciones}

Como ya se ha señalado, en Venezuela la promulgación del CoPP en enero de 1998 marcó el inicio de la reforma procesal, que consistía primordialmente en el cambio del sistema inquisitivo por uno de carácter acusatorio. Tras el nuevo Código, vinieron las nuevas leyes del Ministerio Público (reformada en marzo de 2007) y las subsiguientes legislaciones que rigen al principal órgano de investigaciones del país, el CICPC, que han sido reformadas en los años 2001, 2007 y 2012.

En términos generales, con sus altibajos, en la legislación que rige las investigaciones penales hubo dos grandes pasos que constituyeron un avance significativo en el proceso de reforma, en especial, en lo referente al órgano de investigaciones criminalísticas: 1) El cuerpo encargado de esta función deja de ser policía judicial para convertirse en órgano de investigaciones, y 2) La adscripción funcional de este órgano pasa a estar a cargo del Ministerio Público. No obstante, estos dos significativos avances se han visto severamente afectados por las reformas legislativas del año 2012.

No se puede perder de vista que el contexto de estas reformas es la campaña por la silla presidencial, que como se ha explicado en otras oportunidades (ÁvilA, 2010), al estar inmersas en la emotividad electoral, en donde lo securitario ocupa los primeros lugares de la agenda, la racionalidad autoritaria, de disminución de garantías y de eficientismo mediático, es lo que predomina. Como antecedente de este cocktail no pueden perderse de vista los publicitados "Madrugonazos" implementados a comienzos de 2011, consistentes en la toma de determinadas zonas de la ciudad por el CICPC para realizar redadas, allanamientos, alcabalas, requisa de vehículos y detención de personas. Política que fue seriamente cuestionada a partir del asesinato de tres detenidos en los calabozos del CICPC, en mayo de ese mismo año. Diez meses después, en marzo de 2012, el asesinato de la hija del cónsul chileno en el Estado Zulia, al pasar por una alcabala del CICPC, reavivó el debate sobre las funciones de este cuerpo, lo que sirvió como detonante para acelerar los proyectos de reforma que venían en marcha.

Las recientes reformas legislativas en esta materia, específicamente el Decreto con Rango, Valor y Fuerza de Ley Orgánica del Servicio de Policía de Investigación, el Cuerpo de Investigaciones Científicas, Penales y Criminalísticas y el Servicio Nacional de Medicina y Ciencias Forenses (LOSPI), cuyo solo nombre da indicios de la calidad de la técnica legislativa empleada, que deroga la Ley del CICPC de 2007, junto a la última reforma del COPP, ambos publicados el 15 de junio de 2012, tienen en común el intento por menguar la dirección del Ministerio Público sobre la investigación penal. Tanto en la LOSPI como en la última reforma del COPP hay intencionados pero -afortunadamente- no bien logrados cambios de redacción que intentan restarle protagonismo al rol del Ministerio Público como director de la investigación penal; no obstante, las nuevas redacciones pueden agravar las tensas relaciones existentes entre 
esta institución y el CICPC, dificultando en la práctica el casi imposible control que debe ejercer el primero sobre el segundo. Algunos ejemplos concretos de lo planteado que se encuentran en la LOSPI son los siguientes:

1. En su artículo 19 establece que el "órgano rector" del servicio de policía de investigación es el Ministerio con competencia en materia de seguridad ciudadana; ahora bien, ¿cómo debe interpretarse la relación entre el "órgano rector” (Ministerio de Interior y Justicia) y el director de la investigación penal (Ministerio Público)?;

2. En su artículo 34 intenta suprimir el carácter de director principal de la investigación penal que tiene el Ministerio Público relegando al mismo a las labores eminentemente jurídico-constitucionales, lo que a efectos prácticos (en contra de la voluntad de los legisladores), en vez de reducir su campo de acción, le fortalece, ya que el control de la legalidad está por encima de la labor técnico-científica;

3. En su artículo 50 (que equivale al artículo 11 de la Ley del CICPC de 2007) elimina entre las labores del CICPC la práctica de diligencias ordenadas por el Ministerio Público, aunque las menciona tímidamente en el artículo 35.2;

4. Deroga el artículo 24 de la Ley del CICPC de 2007 que establecía la no remoción de los funcionarios de investigaciones penales o que los mismos no fuesen apartados de la investigación, a no ser por decisión del fiscal del Ministerio Público conforme a las causales establecidas por ley. Lo que se encuentra en sintonía con la supresión de los artículos 114 y 116 del copp de 2009, tal como se explica a continuación.

En el caso de la última reforma del copP también se aprecia esta racionalidad por otorgarle una mayor discrecionalidad al órgano de investigaciones:

1. El artículo 124 ahora establece una excepcionalidad genérica respecto a la titularidad de la acción penal;

2. El artículo 118 elimina el poder disciplinario que tenía el Fiscal General de la República sobre los órganos de investigación consagrados en el artículo 116 del COPP anterior;

3. La supresión del artículo 114 del copp de 2009 que establecía la subordinación de los órganos de policía de investigaciones respecto al Ministerio Público, así como la eliminación de la prohibición que tenía la autoridad administrativa de revocar, alterar o retardar una orden emitida por el fiscal.

Mención especial merecen estos dos últimos puntos, que serían parte de las consecuencias lógicas que derivan de la dependencia funcional del investigador al fiscal, tales como: la imposibilidad de que el investigador pueda ser removido o apartado por su superior jerárquico (Poder Ejecutivo) de la investigación que le hubieren en- 
comendado hasta su finalización, salvo que así lo autorice el fiscal, conforme a las causales establecidas en la ley; así como la imposibilidad que debería tener la autoridad administrativa del CICPC para revocar, alterar o retardar una orden emitida por el fiscal; y, finalmente, que el Fiscal General de la República goce de un poder disciplinario sobre los investigadores del CICPC en caso de negligencias, retrasos y omisiones frente a órdenes que les impartan los fiscales. Estas tres tímidas atribuciones del Ministerio Público, tal como ya se ha señalado ut supra, han sido formalmente derogadas por la actual reforma de 2012, subsistiendo solo el numeral 14 del artículo 25 de la LOMP, que establece entre las atribuciones del Fiscal General de la República la aplicación directa de las sanciones disciplinarias legalmente establecidas a los funcionarios de investigaciones penales, previo cumplimiento del respectivo procedimiento.

Así entonces, si antes todas estas normas no trascendían de la mera formalidad, y se evidenciaba que la adscripción orgánica terminaba prevaleciendo siempre ante la funcional; ahora con las reformas de 2012 se da una vuelta de tuerca más para el establecimiento del Estado de Policía (ZAFFARONI, 2007) y el empoderamiento del órgano de investigaciones.

No obstante, a pesar de la intencionalidad de los reformadores, la deficiente calidad técnica de ambos instrumentos legales en lo que a esta materia se refiere, aunado a una lectura armónica y crítica de los mismos respecto al resto del bloque normativo, en especial con la CRBV y la LOMP, afortunadamente, impide que las intenciones de esta reforma puedan materializarse fácilmente ${ }^{16}$.

A pesar de las reformas legislativas que intentan restaurar el sistema inquisitivo en el país, disminuir los controles sobre el CICPC y otorgarle más poder y discrecionalidad al mismo, es vital para el buen funcionamiento del actual sistema que entre este cuerpo y el Ministerio Público exista una estrecha y clara vinculación. La misma debe ser asumida en términos de subordinación funcional (RoxIN, 2003, p. 57) por parte del CICPC, toda vez que tanto la CRBV (arts. 285, nums. 3 y 4) como el COPP (arts. 111, nums. 1 a 4, 114, 116, 265, 266, 291 y 514, nums. 7 a 9), la LOMP (arts. 16, nums. 3 a 6,25 , nums. 13,14 y 24, 31.11, 37, nums. 6, 9, 10 y 11, y 53.1), la LOSPI (arts. 34, 35 , nums. 2 y 3, y 40) y la LOSPCPNB (art. 33) establecen que quien ordena y dirige la investigación penal es el Ministerio Público.

16 Trágicamente, a menos de una semana de la publicación de la nueva legislación funcionarios del CICPC asesinaron por error a uno de sus compañeros en una alcabala ilegal (http://www.eluniversal. com/sucesos/120622/funcionarios-del-cicpc-mataron-a-un-companero-en-una-alcabala-ilegal), en una práctica muy similar al sonado caso Kennedy del año 2005, perdiendo la nueva legislación su efecto simbólico inmediato. 


\subsubsection{La desjudicialización de la fase de investigación para concebirla como una mera función policial (policialización) de carácter eminentemente tecnocrático}

La intencionalidad política de la nueva LOSPI apunta a la policialización de la fase de investigación, tanto así que la filosofía de esta ley es la concepción de la investigación penal como una parte integrante del servicio de policía (arts. 5 a 7). Esto ratifica que las lógicas securitarias en Venezuela están apuntando más a administrativizar y policializar en vez de judicializar esta fundamental fase del proceso penal.

En este sentido, Roxin advierte sobre el peligro de entregar cada vez más a las policías el procedimiento de investigación en detrimento de la dirección fiscal: "frecuentemente, ella [la policía] conduce las investigaciones autónomamente y sólo cuando están terminadas eleva el expediente a la fiscalía, la que entonces sólo decide si sobresee el procedimiento o promueve la acusación. Esto resulta cuestionable, porque afecta la conducción del procedimiento de investigación por las autoridades judiciales" (2003, p. 70).

Lo anterior se complementa con la necesaria diferenciación entre las labores propiamente policiales y las de investigación. Para ello es importante ratificar que las principales funciones del CICPC deben ser de carácter post delictivo: investigación de delitos e identificación de sus autores y cómplices; en contraste con las labores de las policías uniformadas que son de carácter eminentemente preventivo (ex ante), ocurren antes de que suceda el delito, o en su defecto se constituyen en acciones de contención coetáneas con este (ÁviLA, 2013 y 2012). Por un lado, la LOSPCPNB ya abría el camino en este sentido (arts. 18, num. 12, 37, 39, nums. 1 y 4, y disposición transitoria séptima), al definir claramente las competencias policiales, pudiendo diferenciarse estas de las funciones de investigación; en sintonía con esta idea están los artículos 5 y 53.1 de la LOSPI. Sin embargo, la misma LOSPI presenta contradicciones internas y en ella, como ya se ha explicado, termina imponiéndose una lógica de policialización de la fase de investigación penal, que contribuye más a la confusión entre las labores de prevención y las de investigación. Se policiza cada vez más a los investigadores, usando como plantilla de la nueva legislación a la LOSPCPNB. De esta manera se desconoce lo que ya se ha afirmado en las páginas precedentes: la función policial es distinta a la función de investigar, los investigadores no son policías.

Esta contradicción se evidencia con el fortalecimiento de la adscripción orgánica del CICPC al Ministerio de Interior y Justicia presente en la mencionada ley, situación que representa una continuidad en el sometimiento de esta institución a criterios de seguridad ciudadana, preventivos y de orden público en general. Por ejemplo, ¿cómo el Director del CICPC podría negársele al Ministro de Interior cuando este por "razones de Estado" le ordene efectuar labores de patrullaje, vigilancia de manifestaciones políticas, entre otras? Peor aún, ¿qué pudiera decirle este al Presidente de la República ante semejantes órdenes? Esto último es muy factible, dado que el artículo 14 
de la Ley del Estatuto de la Función de la Policía de Investigación, promulgada el mismo día que la LOSPI y la reforma del copP, establece que el Presidente ejerce la "rectoría" y "dirección" de la función de la policía de investigación. Debido a lo delicado de esta situación, actividades de seguridad ciudadana o de carácter preventivo, que son propiamente funciones policiales, deberían ser claramente diferenciadas de las funciones propias de investigación penal, lamentablemente la nueva legislación agudiza la promiscuidad entre ambas funciones.

El fondo real de esta reflexión crítica es la dicotomía existente entre derechos y justicia, por un lado, y seguridad, por el otro, en la que se aprecian claramente las tensiones entre el Estado Social de Derecho y de Justicia que lucha constante y dialécticamente contra el Leviatán absolutista, o en términos de ZAFFARONI (2007), esto no es más que la lucha entre el modelo del Estado de Derecho y el modelo del Estado de Policía.

\section{REFLEXIONES FINALES}

Al policializar la fase de investigación, la cual -como ya se ha explicado-determina de una manera crucial al juicio y por lo tanto al proceso mismo: se estaría entonces policializando también y de forma considerable al proceso penal en su totalidad. Esto significa una merma considerable del debido proceso y de los derechos y garantías que este abarca; todo ello, en parte, como consecuencia de la disminución de la dirección que debe tener el Ministerio Público sobre la investigación penal. Lo que evidencia no solo el desmontaje progresivo del sistema acusatorio en Venezuela, sino también la tendencia a administrativizar cada vez más al derecho penal tanto sustantivo como adjetivo, en procura del fortalecimiento del Estado de Policía y en detrimento del Estado Social, de Derecho y de Justicia consagrado en la CRBV, a través de la restauración progresiva del sistema inquisitivo en el país.

\section{REFERENCIAS}

Ávila, K. (2013). "Campañas securitarias: el órgano de investigaciones criminalísticas”. En Espacio Abierto, vol. 22, n. ${ }^{\circ}$ 3:701-730. Venezuela. LuZ. Disponible en: http://revistas.luz.edu.ve/index.php/ea/article/view/16198.

Ávila, K. (2012). “PPolicía de investigación? Reflexiones sobre la naturaleza de su función y órgano de adscripción”. En: Comunes, Revista de Seguridad Ciudadana y Pensamiento Crítico n. ${ }^{\circ}$ 1. Venezuela: Universidad Nacional Experimental de la Seguridad.

ÁvilA, K. (2010). "La instrumentalización del delito: política, empresas de comunicación e inseguridad. Sobre cómo la inseguridad logró posicionarse en el primer lugar de la agenda pública en Venezuela”. En: Espacio Abierto, vol.19, n. 2:297329. Venezuela: Luz. Disponible en: http://www.revistas.luz.edu.ve/index.php/ea/ article/viewFile/4639/4514 
Binder, A. (1993). Introducción al Derecho Procesal Penal. Buenos Aires: Ad-Hoc.

CAncio, M. (2006). “De nuevo: ¿'Derecho penal' del enemigo?”. En: Jakobs, G. I CAncio, M. Derecho Penal del Enemigo. España: Aranzadi.

CANCiO, M. / GÓMEZ-JaRa, C. (2006b). Derecho penal del enemigo. El discurso penal de la exclusión. Vol. 1. España: Edisofer / Editorial B de F.

CARlés, R. (2013). El gobierno local del delito en la Ciudad Autónoma de Buenos Aires: retóricas participativas y policialización de la cuestión securitaria. Informe final presentado al Consejo Latinoamericano de Ciencias Sociales, Beca CLACSOAsdi 2011-2012, en curso de publicación.

FERRAJOLI, L. (2001). Derecho y razón: teoría del garantismo penal. Trad. IBÁÑEZ, P./ Ruíz, A. /BAyón, J./ Terradillos. B. / CAnTArero, R. 5. a ed. Madrid: Trotta, 1995. Título original: Diritto e ragione. Teoria del garantismo penale.

GARCíA A., J. (2006). "El obediente, el enemigo, el derecho penal y Jakobs": pp. 187-924. En: CANCIO, M. / GómEZ-JARA, C. Derecho penal del enemigo . El discurso penal de la exclusión. Vol. 1. España: Edisofer / Editorial B de F.

Gimeno SEndRA, V. (1988). “Algunas sugerencias sobre la atribución al Ministerio Fiscal de la Investigación Oficial”. Revista Justicia n. IV.

Jakobs, G. / Cancio, M. (2006). Derecho Penal del Enemigo. España: Aranzadi.

JAKOBS, G. (2004). "La autocomprensión de la ciencia del Derecho penal ante los desafíos del presente”. En: EsEr, A. / HASSEMER, W. / BurkHARdt, B. (coords.). Las ciencias del Derecho penal ante el nuevo milenio. Valencia: Tirant lo Blanch.

MARTín y MARTín, J. (2004). La instrucción penal. Madrid: Marcial Pons.

Mir Puig, S. (1994). El Derecho Penal en el Estado Social y Democrático de Derecho. Barcelona: Ariel.

PÉrez Martínez, R. (1998). “La policía judicial en el Estado democrático de derecho”. Policía y Sociedad Democrática n. ${ }^{\circ}$ 3:155-172. Buenos Aires: Editores del Puerto.

Pérez Sarmiento, E. (2007). Comentarios al Código Orgánico Procesal Penal. 5. ${ }^{a}$ ed. Venezuela: Vadell hermanos.

República Bolivariana de Venezuela (2012). Decreto con Rango, Valor y Fuerza de Ley del Estatuto de la Función de la Policía de Investigación. G.O. n. . 39.945. 
República Bolivariana de Venezuela (2012). Decreto con Rango, Valor y Fuerza de Ley Orgánica del Servicio de Policía de Investigación, el Cuerpo de Investigaciones Científicas, Penales y Criminalísticas y el Servicio Nacional de Medicina y Ciencias Forenses. G.O.E. n. ${ }^{\circ} 6.079$.

República Bolivariana de Venezuela (2012). Decreto con Rango, Valor y Fuerza de Ley del Código Orgánico Procesal Penal. G.O.E. n. ${ }^{\circ} 6.078$.

República Bolivariana de Venezuela (2009). Ley Orgánica del Servicio de Policía y del Cuerpo de Policía Nacional Bolivariana. G.O. n. ${ }^{\circ} 5.940$.

República Bolivariana de Venezuela (2009). Código Orgánico Procesal Penal. G.O.n. ${ }^{\circ} 5.930$.

República Bolivariana de Venezuela (2007). Ley del Cuerpo de Investigaciones Científicas, Penales y Criminalísticas. G.O. n. ${ }^{\circ} 38.598$.

República Bolivariana de Venezuela (2007). Ley Orgánica del Ministerio Público.G.O. n. ${ }^{\circ} 38.647$.

República Bolivariana de Venezuela (2001). Ley Orgánica del Poder Ciudadano. G.O.n. ${ }^{\circ} 37.310$.

República Bolivariana de Venezuela (2000). Constitución de la República Bolivariana de Venezuela. G.O.E. n. ${ }^{\circ} 5453$.

RiEgo, C. (1999). "Las reformas judiciales y la seguridad ciudadana". En Revista Perspectivas en política, economía y gestión. n. ${ }^{\circ}$ 1, año 1999. Chile: Universidad de Chile.

RIVERA, R. (2008). Actos de investigación y pruebas en el proceso penal. Barquisimeto, Venezuela: Universidad Católica del Táchira, Librería J. Rincón.

Roxin, C. (2003). Derecho Procesal Penal. Buenos Aires: Editores del Puerto.

Sain, M. (2008). El Leviatán Azul. Policía y Política en la Argentina. Buenos Aires: Siglo XXI Editores Argentina.

Silva SÁnchez, J. (2006). La expansión del derecho penal: Aspectos de la Política criminal en las sociedades postindustriales. Montevideo-Buenos Aires: Euros Editores S.R.L.-B de F Ltda. 
VÁSQUEZ, M. (2003). “Actos de investigación y actos de prueba” En: Sextas Jornadas de Derecho Procesal Penal. Temas actuales de Derecho Procesal Penal 27, 28 y 29 de mayo. Venezuela: Universidad Católica Andrés Bello.

WEBER, M. (1904). La objetividad del conocimiento en la ciencia y de las políticas sociales.

Wilson, J. / Kelling, G. (1982). "Broken Windows. The police and neighborhood safety" En: The Atlantic Monthly, Volumen 249, n. . 3: 29-38. Traducción al castellano de Fridman, D. (2001) "Ventanas rotas. La policía y la seguridad de los barrios", en

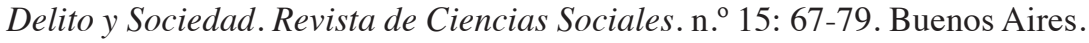

Zaffaroni, E./ Slokar, A./ Alagia, A. (2007). Manual de Derecho Penal. 2da ed, 1era reimp. Buenos Aires: EDIAR.

Zaffaroni, R. (1998). En busca de las Penas Perdidas. Buenos Aires: EDIAR S.A.

ZERPA, A. (2007). "Revisión de Alguno de los Derechos Consagrados en la Garantía al «Debido Proceso» en su relación con el Proceso Penal Venezolano". En: Debido Proceso y Medidas de Coerción Personal. X Jornadas de Derecho Procesal Penal. Caracas: UCAB. 